\title{
A note on pessimism in education and its economic consequences
}

\author{
Karol Mazur ${ }^{1}$
}

Received: 20 October 2019 / Accepted: 9 March 2021 / Published online: 10 August 2021

(C) The Author(s) 2021

\begin{abstract}
Investigating interaction of the lumpy nature of educational investments and informational frictions on returns to and costs of education, I show that pessimistic beliefs can be selfconfirmed in equilibrium. Among some of its consequences, I argue that the commonly pursued research methods may not always identify the true underlying skill distributions.
\end{abstract}

Keywords Human capital · Education · Self-confirming equilibrium · Beliefs $\cdot$ Pessimism

\section{Introduction}

Beliefs about net returns to education constitute perhaps the most important determinant of educational investment decisions. The very nature of these investments being rare and taking a lot of effort, time and money to deliver a positive net pay-off, suggests that these investments may be lumpy. As such, we cannot expect people to get their decisions right by trial-and-error or by making marginal adjustments.

Recent empirical work in economics of education has documented significant biases in beliefs about net returns to college education. A common conclusion flowing from this literature is that these beliefs are often pessimistic, ${ }^{1}$ and are correlated with households' socio-economic status. ${ }^{2}$ Building on these premises, many papers have gone on to investigate effectiveness of interventions addressing these informational frictions with the ultimate goal of improving the equality of opportunity and allocation of talent. ${ }^{3}$

${ }^{1}$ Cf. Ikenberry and Hartle (1998), Horn, Chen and Chapman, Jensen (2010).

${ }^{2}$ Cf. Betts (1996), Ikenberry and Hartle (1998), Horn et al. (2003), Grodsky and Jones (2007), Bleemer and Zafar (2018), Boneva and Rauh (2018, 2019).

${ }^{3}$ Cf. Nguyen (2008), Jensen (2010), Hoxby and Turner (2013, 2015), Dinkelman and Martinez (2014), Wiswall and Zafar (2015a, b), Bleemer and Zafar (2018), Dynarski et al. (2018), Porter and Serra (2020).

Karol Mazur

karol.mazur@trinity.ox.ac.uk

1 Trinity College, University of Oxford, Oxford, UK 
In this note, I show that in the presence of uncertainty about the true returns to lumpy educational investments, pessimistic beliefs may persist in the long-run due to being selfconfirmed in equilibrium (in the sense of Fudenberg and Levine 1993). ${ }^{4}$ In particular, since pessimistic individuals may underinvest in education, they will receive labor income confirming their pessimistic priors in equilibrium. This is at odds with optimistic agents, who may overinvest in education and find out about their beliefs being upwardly biased through receiving lower than expected labor income.

The general idea behind the main assumption of this note is that education cannot be varied by small amounts, as warranted by extensive empirical evidence in the literature (discussed in Section 2.1). This can be due to the actual years of schooling being bunched around years associated with the completion of primary, secondary or higher education. Similarly, pay-offs from pursuing different professions are often concentrated at different levels. Theoretically, the lumpy investment profile may arise due to non-convex education adjustment costs or information asymmetries.

Based on the self-confirmation result, I discuss further possible implications of the interaction between lumpy educational investments and pessimistic biases. First, the selfconfirming nature of pessimistic beliefs implies that it may not be possible to identify the true inborn skill distributions without identifying the underlying beliefs of students or their parents. Second, I argue that pessimism may have large negative consequences on long-run economic growth due to dynamic complementarities between education and production sectors. Finally, the interaction of self-confirming equilibria realized at the microand macro-levels may lead to election of politicians implementing suboptimal economic policies.

This note is organized as follows. In Section 2, I present the main self-confirmation result using a simple economic model. I discuss economic implications of this finding in Section 3. Then, Section 4 discusses potential robustness of the main theoretical result to alternative assumptions on beliefs and various learning algorithms. Section 5 concludes.

\section{Model economy}

\subsection{Objective beliefs}

Consider an agent who lives for two periods and values consumption $c \geq 0$ according to the utility function $u(c)$ satisfying $u^{\prime}(c)>0, u^{\prime \prime}(c) \leq 0$ and dislikes exerting educational effort $e \geq 0$ according to the disutility function $v(e)$ with $v^{\prime}(e), v^{\prime \prime}(c)>0$. In particular, she maximizes the following quantity:

$$
-v(e)+\mathrm{E} u(c)
$$

where $\mathrm{E}$ is the objective expectations operator.

In period 1, the student makes a decision about the level of her effort investment into education $e$, which can be thought of as deciding on the whole path of education: from high school to finishing a Ph.D. Crucially, the human capital accumulation process is governed

\footnotetext{
${ }^{4}$ See also Cho and Sargent (2008).
} 
by the $N$-step function $\theta(e)$ :

$$
\theta(e)= \begin{cases}\underline{\theta} & \text { if } e \in\left[0, q_{1}\right) \\ \theta\left(q_{1}\right) & \text { if } e \in\left[q_{1}, q_{2}\right) \\ \cdots & \ldots \\ \theta\left(q_{N}\right) & \text { if } e \in\left[q_{N}, 1\right]\end{cases}
$$

where $\underline{\theta}>0$ stands for the minimum level of human capital attainable without exerting any further effort (e.g. finishing at high school education). ${ }^{5}$

In the second period, after the student graduates, she earns and consumes all of the wage income $w \cdot \theta(e)$, where $w$ is the exogenously given market wage. ${ }^{6}$

In equilibrium, the student will optimally exert effort at the level level $e^{*} \in\left\{0, q_{1}, \ldots, q_{N}\right\}$ maximizing their expected utility, i.e. according to:

$$
e^{*}=q_{i}:-v\left(q_{i}\right)+\mathrm{E} u\left(c_{2}^{*} \mid q_{i}\right) \geq-v\left(q_{j}\right)+\mathrm{E} u\left(c_{2} \mid q_{j}\right) \forall j \neq i
$$

Modeling returns to education as a step-function is in line with extensive empirical literature in labor economics documenting "sheepskin effects" in labor markets, i.e. significantly larger returns to diploma years compared to in-between years of education (Hungerford and Solon 1987; Belman and Heywood 1991; Heckman et al. 1996, 2008; Jaeger and Page 1996). Common explanations of these effects include (i) the signaling value associated with obtaining degrees, (ii) selection of individuals into graduation based on unobservables (to both econometricians and students themselves), (iii) the holistic nature of human capital accumulation process, or (iv) a combination of all the previous factors. ${ }^{7}$

Furthermore, the educational investment profile could become lumpy endogenously as an optimal decision made by students facing uncertainty about the true return function and costly information acquisition along the lines of rational inattention literature. In particular, this could be the case even if the optimal profile without rational inattention was continuous (see the work of Matejka 2015; Jung et al. 2019).

\subsection{Subjective beliefs}

Differently to the allocation above, I consider now an agent deciding about her education under an optimistic or pessimistic subjective belief operator as defined below:

\section{Assumption 1. (subjective beliefs)}

- Optimistic belief $\mathrm{E}^{\mathbf{S}}(\theta(\mathbf{e}))$ : return function $\theta(e)$ is a step function as in Eq. 1 with $N^{O}>N$ steps s.t. $\mathrm{E}^{S}\left(\theta\left(q_{i}\right)\right)=\theta\left(q_{i}\right)$ for $N$ steps and $\mathrm{E}^{S}\left(\theta\left(q_{i}\right)\right)>0$ for remaining $N^{O}-N$ steps.

- Pessimistic belief $\mathrm{E}^{\mathbf{S}}(\theta(\mathbf{e}))$ : return function $\theta(e)$ is a step function as in Eq. 1 with $N^{P}<N$ steps s.t. $\mathrm{E}^{S}\left(\theta\left(q_{i}\right)\right)=\theta\left(q_{i}\right), i=1, \ldots, N^{P}$.

Consequently, the optimal educational effort is chosen according to:

$$
e^{*}=q_{i}:-v\left(q_{i}\right)+\mathrm{E}^{S} u\left(c_{2}^{*} \mid q_{i}\right) \geq-v\left(q_{j}\right)+\mathrm{E}^{S} u\left(c_{2} \mid q_{j}\right) \forall j \neq i
$$

\footnotetext{
${ }^{5}$ In order to maintain clarity of the argument, the human capital accumulation process (1) abstracts from factors such as monetary inputs or institutional environment, which are certainly very important in reality.

${ }^{6}$ Theoretically, wages are pinned down by a linear constant returns to scale technology. Thus, I ignore the impact of changes in supply on the wages associated with schooling.

${ }^{7}$ For a broader review of this literature, see Huntington-Klein (2020).
} 
Figure 1 presents an illustration of Assumption 1 with lumpy objective (with $N=4$ ), subjective pessimistic (with $N^{P}=3$ ) and subjective optimistic (with $N^{O}=7$ ) beliefs on returns to education. This example can be thought of as presenting objective returns associated with pursuing only high school (with no effort supplied), 2 year community college, 4 year community college, graduate or $\mathrm{Ph} . \mathrm{D}$. education.

The pessimist does not believe in positive returns associated with attending a 2 year community college (e.g. due to the common perception of serving only as a stepping stone for transferring to a 4-year college ${ }^{8}$ ). Alternatively, if the missing step was at a higher level, it could be due to the pessimist not acknowledging the additional value of completing graduate or Ph.D. programs (e.g. due to being less common in the population, and so being harder to form a belief on). On the other hand, the optimist believes in 3 additional levels of educational investments that are not as productive as believed in (e.g. some short courses ending with certificates).

In practice, such biases may arise for a variety of reasons ranging from a lack of role models (Nguyen 2008; Porter and Serra 2020), imperfect information about available financial aid (Roderick et al. 2009; Johnson et al. 2011; Dynarski et al. 2018), its administrative complexity (Bettinger et al. 2012), poverty generating aspiration failures (Ray 2006; Dalton et al. 2016; Genicot and Ray 2017), to simply being generated by media reports of students burdened by their loans (Advisory Committee on Student Financial Assistance 2001). Finally, findings in the literature studying effects of perceived returns to effort support the modeling assumption of human capital accumulation depending on students' beliefs (Azmat and Iriberri 2010; Stinebrickner and Stinebrickner 2014; Bandiera et al. 2015; Azmat et al. 2019; Ersoy 2019).

\subsubsection{Self-confirming equilibrium}

In what follows, I argue that the equilibrium associated with a subjective pessimistic belief system may be self-confirming. Adapting insights of Fudenberg and Levine (1993) to the setting of this note, the self-confirming equilibrium is characterized by the coincidence of subjective and objective beliefs on the equilibrium path (i.e. $\mathrm{E}^{S}\left(\theta\left(e^{*}\right)\right)=\theta\left(e^{*}\right)$, where $e^{*}$ is the equilibrium effort choice), but not necessarily off the equilibrium path (i.e. $\exists e^{\prime} \neq$ $\left.e^{*}: \mathrm{E}^{S}\left(\theta\left(e^{\prime}\right)\right) \neq \theta\left(e^{\prime}\right)\right)$. See Supplementary Material for a formal definition of the self-confirmed equilibrium. Formally, we have that:

Proposition 1 The allocation associated with a pessimistic subjective belief system, that fits the definition in Assumption 1, constitutes a self-confirmed equilibrium.

\section{Proof See Supplementary Material.}

Intuitively, since pessimism limits educational achievements of the student, her belief is confirmed by the labor market experience. But had the student experimented by pursuing an off-equilibrium educational investment decision, she could find out that her subjective beliefs were wrong.

Returning to the example in Fig. 1, the optimal effort decision of the pessimistic student will be one of $0,0.25,0.5$ or 0.75 , and of the optimistic student - one of $0,0.1,0.25,0.375$, $0.5,0.625,0.75$ or 0.875 . For the purpose of argument, let us assume that the $u(\cdot)$ and $v(\cdot)$

\footnotetext{
${ }^{8}$ See Trachter (2015) for analysis of this phenomenon in the US.
} 


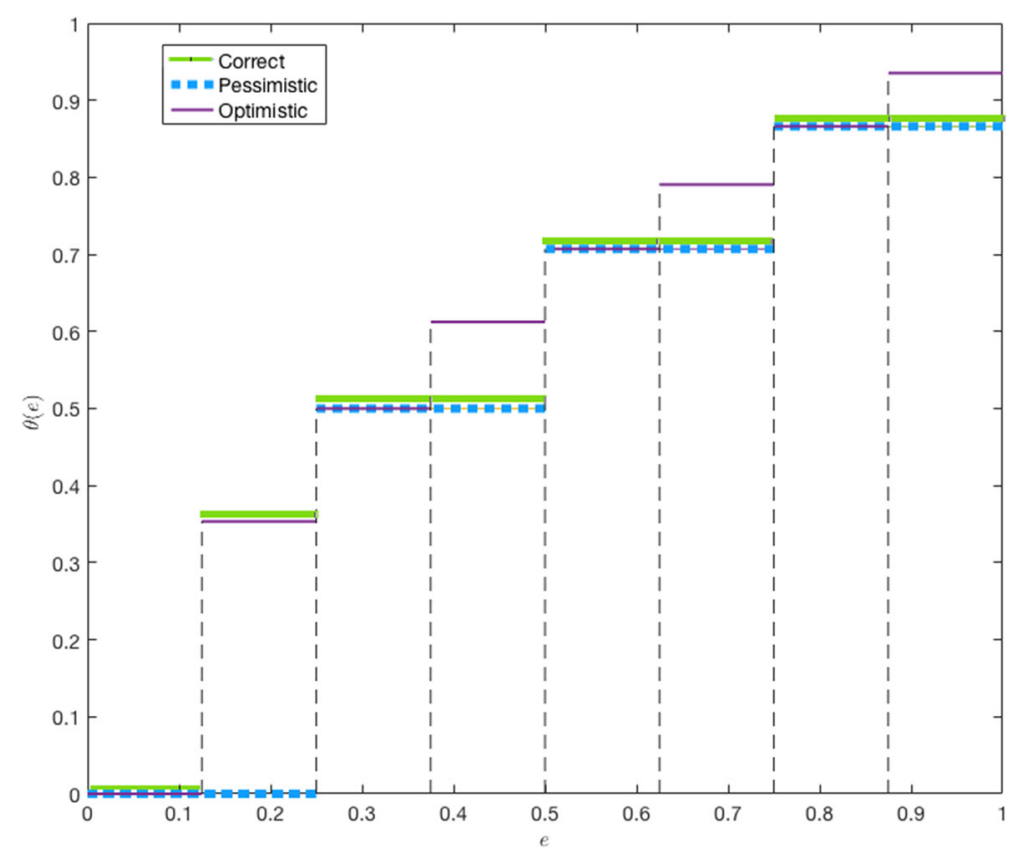

Fig. 1 Example of objective, pessimistic and optimistic beliefs on returns to education

functions are s.t. the pessimistic student finds it optimal to invest at the level of $e^{*}=0.25$, and the optimistic agent at the level of $e^{*}=0.375$. Although an investment of $e^{*}=0.25$ produces equilibrium labor income of $0.5 \cdot w$ that is perfectly in line with beliefs of the pessimistic agent, an off-equilibrium experimental choice of $e^{\prime}=0.25-\epsilon$ would produce a return of $0.375 \cdot w\left(=\theta\left(e^{\prime}\right) \cdot w\right) \neq 0\left(=\mathrm{E}^{S}\left(\theta\left(e^{\prime}\right)\right) \cdot w\right)$, refuting the pessimistic belief. On the other hand, an investment of the optimistic agent at the level of $e^{*}=0.375$ will be corrected in equilibrium as she will earn $\theta\left(e^{\prime}\right) \cdot w=0.5 \cdot w$, below the expected income of $\mathrm{E}^{S}\left(\theta\left(e^{\prime}\right)\right) \cdot w=0.6 \cdot w$.

At this point, four further comments are due. First, notice that the discussion of allocations with both the objective and subjective beliefs are consistent with the equilibrium concept I focus on here since every rational expectations (i.e. with objective beliefs) equilibrium is a self-confirming equilibrium (but not vice versa).

Second, because in the self-confirming equilibrium agent's prior beliefs are confirmed, they have no incentives to experiment in this simple static framework. However, one could extend it into a repeated decision problem (for with multiple stages of education or overlapping generations) and introduce motives for experimenting with off-equilibrium path decisions. Fudenberg and Levine (2006) show that in such a framework beliefs of biased agents (or their future generations) could indeed converge to the objective ones under two conditions: (1) if agents were sufficiently patient, and (2) if the educational decision was taken sufficiently often. Unfortunately, in reality the educational decisions are taken rather rarely and as such the biased beliefs can well survive in the long-run. Returning to the example in Fig. 1, if the model was extended to allow for repeated educational decision, experimentation could lead the pessimistic agent to learn what the objective returns to education look like and so lead to a different optimal choice. On the other hand, the optimistic 
agent will learn about her mistake as soon as she receives labor income below her expectations. Thus, in such a framework, the optimistic agent could achieve better outcomes than the pessimistic one if experimentation was prohibitively costly.

Third, notice that a pessimistic belief system can in principle lead students to choose education at levels both above or below the ones chosen under objective beliefs. Nonetheless, I refer to such beliefs as pessimistic due to the very fact that such a decision would be due to underestimating returns to education at lower levels and as such would lead to a strictly lower lifetime utility.

Finally, the result of self-confirmed pessimism is related to a number of theoretical papers. Dalton et al. (2016) show that poorer individuals are more likely to suffer from a low-effort aspirations failure. ${ }^{9}$ Their analysis rests on a model where aspirations and effort are jointly determined in equilibrium, but the former are taken as given. These features imply that agents end up in a self-confirmed equilibrium similar to the one analyzed here, ${ }^{10}$ without figuring out the endogeneity of aspirations. ${ }^{11}$

Furthermore, the difference in beliefs between the pessimist and optimist, and the associated equilibrium choices, could stem from different reference points, e.g. due to agent's parents having attended college or not. To this end, Koszegi (2010) develops a related solution concept of the personal equilibrium where multiple equilibria are possible, depending on reference points of agents. ${ }^{12}$ If these points are exogenous, decisions taken in the personal equilibrium are maximizing agent's utility - similarly as decisions made under the pessimistic beliefs that maximize subjective utility ${ }^{13}$ in the self-confirming equilibrium studied here.

\section{Implications}

\subsection{Identification of underlying skill distributions}

Following the insights of Saez (2001), it is a common practice nowadays in public finance to infer the underlying skill distributions using observed income distributions. The results above imply that without pinning down the beliefs on net returns to education, the true inborn skill distribution cannot be identified (but rather its lower bound). While this identification problem need not apply to researchers interested in eliciting the post-education skill distributions, it certainly is a very relevant issue in research where an endogenous human capital accumulation process plays a central role.

Therefore, it would be interesting to verify the optimal policy prescriptions derived in the literature when the pessimistic beliefs are properly accounted for. Obviously, this is not to say that we should tax or subsidize people differently based on their past mistakes. However, it might be worthwhile to investigate the size of social welfare losses in human capital models that may be prescribing sub-optimal policies due to ignoring the deeply rooted problem of biased beliefs.

\footnotetext{
${ }^{9}$ Defined as failing to achieve what is best and feasible for them.

${ }^{10}$ The difference in this note is that the self-confirmed equilibrium effort choice of pessimistic agents can be both below or above the one chosen under objective beliefs.

${ }^{11}$ See also Dalton and Ghosal (2018) for a more general treatment of these issues.

${ }^{12}$ See also Koszegi and Rabin (2006).

${ }^{13}$ But not the objective one.
} 


\subsection{Long-run economic growth}

Constraints on human capital accumulation imposed by pessimistic beliefs may have important implications for long-run economic growth. This is especially so in light of a dynamic complementarity between human capital accumulation and firms' technology adoption (or R\&D) exposed theoretically by Lloyd-Ellis and Roberts (2002) and Stokey (2018), and empirically by Hanushek and Woessman (2008) and Hsieh and Klenow (2010). On one hand, without sufficiently high technological progress, workers would face lower incentives to acquire new skills. On the other, in face of the reduced skill supply, firms would reduce their technological investments. In face of this intertwined relationship, pessimistic beliefs may constitute a particularly large drag on the long-run economic growth.

\subsection{Political economy}

Piketty (1995), Alesina and Angeletos (2005) and Benabou and Tirole (2006) develop political economy models where workers face the problem of identifying the true impact of effort and luck on the income received. This leads some dynasties to believe that economic outcomes are predominantly determined stochastically and some that it rather depends on their labor effort, implying different preferences over the degree of public insurance which is pinned down in equilibrium using the median voter theorem. Because these policies feed back into agents' labor effort decisions, the identification problem gives rise to a set of self-confirmed equilibria with different efficiency and inequality levels.

Given that expectations are an important factor determining educational investments (Wiswall and Zafar 2015b, 2016; Bleemer and Zafar 2018; Boneva and Rauh 2018, Belfield et al. 2019), and that the level and variance of labor income significantly varies between education groups (Meghir and Pistaferri 2004), the interaction of self-confirmed microlevel pessimism and the macro-level political economy equilibria may result in election of politicians implementing economic policies further undermining incentives for effort.

\section{Robustness}

In what follows, I first discuss robustness of the self-confirmed equilibrium result to potential deviations from main modeling assumptions. Then, I go on to discuss some dynamic environments in which the self-confirmed beliefs may well survive in spite of students having ways to learn the truth.

\subsection{Assumptions on objective and subjective beliefs}

Relative to Assumption 1, an alternative way of defining pessimism is to consider a subjective profile of returns that is strictly below the objective one. Under this assumption, the student will always be positively surprised by her returns to education, breaking the result of self-confirmation. While in the above the student was assumed to have a degenerate unitary belief system, it might be more realistic to assume that students' prior on returns to educational investments consists of a distribution of return functions with corresponding subjective probabilities. ${ }^{14}$ In such a case, false pessimistic beliefs could remain stable

\footnotetext{
${ }^{14}$ A source of such a diffused prior could be e.g. uncertainty about one's innate ability or about net returns to education.
} 
whenever the average return coincided with the average belief (as in the Berk-Nash equilibrium concept in Esponda and Pouzo 2016), adding to the robustness of the self-confirmation result. However, while this would certainly hold in the static setup studied here, such a dispersed prior could be a source of incentives to experiment if the educational decision was to be repeated. ${ }^{15}$

Furthermore, many papers in the literature work with continuous human capital accumulation functions, which can be thought of as a limiting case of the step return function considered here. Notice that the presence of flat regions in the subjective return function is a necessary condition for the self-confirmation result. Because of this, this note's main result would survive with a continuous objective return function only if the subjective belief on returns is a step function.

Finally, notice that the model above has assumed that educational outcomes depend only on the student's own effort. Since peer effects ${ }^{16}$ may enable some individuals to achieve educational results and a career they initially did not even think of, they may well break the self-confirmed pessimism. However, a necessary condition for this to happen is that the peer externalities are strong enough to push pessimistic students to the next notch of achievements.

\subsection{Learning algorithms}

Consider first a possibility of learning through observed market outcomes in a richer version of the model with endogenized wage rates ${ }^{17}$ and agents differing in their inborn ability affecting the rate of returns to educational effort. Not unrealistically, let us also assume that the distribution $\Omega$ of ability in the population is unobservable. ${ }^{18}$ In such a framework, conditional on observing a realized vector of market wage income $\theta \cdot \mathbf{w}$ that is not in line with a student's expectation, she can come up with a wrong prior $\tilde{\Omega}$ supporting her subjective beliefs, and so the self-confirmed equilibrium. For instance, such a dynamic could be due to students suffering from the confirmation bias.

Alternatively, students may also have an opportunity to acquire information about returns to education, but processing it can be costly - as in the model of rational inattention with discrete choices by Matejka and McKay (2015). If we were to write a version of their model with students differing in their wealth and returns to education being the only uncertain choice-relevant variable, the poorer students would acquire more information as compared to their richer peers. This would arise as the overall utility gain from educating would be higher for the poorer students due to higher marginal utility associated with each additional unit of the post-education income and consumption.

However, it is arguably more realistic to consider an environment with a fixed amount of attention available that has to be allocated between consumption and education margins. The latter could be thought of as uncertainty about prices of consumption goods, or simply a

\footnotetext{
15 See the discussion on experimentation in Section 2.

${ }^{16}$ Peer effects could be introduced though a human capital accumulation function satisfying $\frac{\partial \theta_{i}(\mathbf{e})}{\partial e_{j}} \neq 0, i \neq$ $j$ and $\mathbf{e}$ being a vector of population efforts.

${ }^{17}$ One way of generating wage rates that are endogenous to supply of skill in the economy is to assume that competitive firms employ different types of workers (e.g. high- and low-skilled) that are imperfectly substitutable, as e.g. in Matsuda and Mazur (2020).

${ }^{18}$ While students may know their own ability, it is necessary for the sake of argument that they do not know the population's true distribution $\Omega$.
} 
difference between consumption preferences in the short- and long-run. Since errors in consumption decisions would be much more painful for poorer households (as they would not be able to smooth these errors so well with their assets), they would allocate less attention to information acquisition on the true returns to education, relative to richer households. In such a case, pessimism among the disadvantaged groups would not only persist, but could also become deeper relative to the rest of society. 19

\section{Conclusion}

In this short note, I analyze the interaction of biased beliefs about returns to educational attainment and lumpy returns to education. Using a simple two period human capital model, I argue that pessimistic beliefs (defined as a belief ignoring positive returns associated with some steps of education) may be self-confirmed in equilibrium. In a nutshell, while beliefs of optimists are likely to be corrected upon entering the labor market and earning less than expected, this need not be the case with pessimists. Because pessimistic beliefs may curb educational investments, pessimists are likely to receive labor income confirming their beliefs. Thus, pessimism may persist in the long-run.

This result has profound implications. First, it shows that the commonly pursued in the literature methods of identifying inborn ability distributions may not be valid. Second, in light of dynamic complementarities between human capital accumulation and technological investments by firms, pessimism may significantly slow down the rate of long-run economic growth. Third, because educational outcomes have significant impact on economic wellbeing of individuals and their relative position in the society, pessimists may be inclined to vote for politicians implementing sub-optimal policies, which can be cementing pessimism even further.

Finally, since the main argument of this note is derived in a stylized environment, I discuss robustness of the self-confirmed equilibrium result to alternative assumptions on subjective and objective beliefs about returns to education. Similarly, I outline some learning environments where the true shape of the return function may remain unlearnable.

Supplementary Information The online version contains supplementary material available at https://doi.org/10.1007/s10888-021-09486-7.

Acknowledgements I am grateful to two anonymous referees for their valuable feedback. My further thanks for insightful discussions are due to Arpad Abraham, Alkiviadis Georgiadis Harris, Wouter den Haan, Caroline Hoxby, Philipp Kircher, Ramon Marimon, Kazushige Matsuda, Josue Ortega, Franz Ostrizek, Luis Rojas, Florian Scheuer and Mirko Wiederholt. An intermediate version of this note was prepared while I was visiting the economics department of the London School of Economics. Its hospitality and assistance are gratefully acknowledged. All remaining errors are my own.

\section{Declarations}

Conflict of Interests The author declares that he has no conflict of interest.

Open Access This article is licensed under a Creative Commons Attribution 4.0 International License, which permits use, sharing, adaptation, distribution and reproduction in any medium or format, as long as you give

\footnotetext{
${ }^{19} \mathrm{~A}$ similar mechanism of attention allocation between different products is studied by Kacperczyk et al. (2016) in the context of mutual funds managers.
} 
appropriate credit to the original author(s) and the source, provide a link to the Creative Commons licence, and indicate if changes were made. The images or other third party material in this article are included in the article's Creative Commons licence, unless indicated otherwise in a credit line to the material. If material is not included in the article's Creative Commons licence and your intended use is not permitted by statutory regulation or exceeds the permitted use, you will need to obtain permission directly from the copyright holder. To view a copy of this licence, visit http://creativecommons.org/licenses/by/4.0/.

\section{References}

Advisory Committee on Student Financial Assistance: Access denied: Restoring the nation's commitment to equal educational opportunity department of education. Washington, D.C (2001)

Alesina, A., Angeletos, G.: Fairness and redistribution. Am. Econ. Rev. 95(4), 960-980 (2005)

Azmat, G., Bagues, M., Cabrales, A., Iriberri, N.: What you don't know... Can't hurt you? A field experiment on relative performance feedback in higher education. Manag. Sci. 65(6) (2019)

Azmat, G., Iriberri, N.: The importance of relative performance feedback information: Evidence from a natural experiment using high school students. J. Public Econ. 94, 435-452 (2010)

Bandiera, O., Larcinese, V., Rasul, I.: Blissful ignorance? A natural experiment on the effect of feedback on students' performance. Labour Econ. 34, 13-25 (2015)

Belfield, C., Boneva, T., Rauh, C., Shaw, J.: What drives enrollment gaps in further education? The role of beliefs in sequential schooling decisions. Economica 87(346), 490-529 (2019)

Belman, D., Heywood, J.: Sheepskin effects in the returns to education: An examination of women and minorities. Rev. Econ. Stat. 73(4), 720-724 (1991)

Benabou, R., Tirole, J.: Belief in a Just World and Redistributive Politics. Q. J. Econ. 121(2), 699-746 (2006)

Bettinger, E., Long, B., Oreopoulos, P., Sanbonmatsu, L.: The role of simplification and information in college decisions: Results and implications from the H\&R block FAFSA experiment. Q. J. Econ. 127(3), $1205-1242$ (2012)

Betts, J.: What do students know about wages? evidence from a survey of undergraduates. J. Hum. Resour. 31(1), 27-56 (1996)

Bleemer, Z., Zafar, B.: Intended college attendance: Evidence from an experiment on college returns and costs. J. Public Econ. 157, 184-211 (2018)

Boneva, T., Rauh, C.: Parental beliefs about returns to educational investments - the later the better? J. Eur. Econ. Assoc. 16(6), 1669-1711 (2018)

Boneva, T., Rauh, C.: Socio-economic gaps in university enrollment: The role of perceived pecuniary and non-pecuniary returns, working paper (2019)

Cho, I.-K., Sargent, T.: Self-confirming equilibria. The new palgrave dictionary of economics. In: Durlauf, S.N., Blume, L.E. (eds.) 2nd edn. (2008)

Dalton, P., Ghosal, S.: Self-fulfilling mistakes: characterization and welfare. Econ. J. 128(609), 683-709 (2018)

Dalton, P., Ghosal, S., Mani, A.: Poverty and aspirations failure. Econ. J. 126(590), 165-188 (2016)

Dinkelman, T., Martinez, C.: Investing in schooling in chile: the role of information about financial aid for higher education. Rev. Econ. Stat. 96(2), 244-257 (2014)

Dynarski, S., Libassi, C., Michelmore, K., Owen, S.: Closing the gap: the effect of a targeted, tuition-free promise on college choices of high-achieving, low-income students, NBER Working Paper No. 25349 (2018)

Ersoy, F.: Effects of perceived productivity on study effort: evidence from a field experiment, available at SSRN: https://ssrn.com/abstract=3253978 (2019)

Esponda, I., Pouzo, D.: Berk-Nash equilibrium: a framework for modeling agents with misspecified models. Econometrica 84(3), 1093-1130 (2016)

Fudenberg, D., Levine, D.: Self-confirming equilibrium. Econometrica 61(3), 523-545 (1993)

Fudenberg, D., Levine, D.: Superstition and rational learning. Am. Econ. Rev. 96(3), 630-651 (2006)

Genicot, G., Ray, D.: Aspirations and inequality. Econometrica 85(2), 489-519 (2017)

Grodsky, E., Jones, M.T.: Real and imagined barriers to college entry: Perceptions of cost. Soc. Sci. Res. 36(2), 745-766 (2007)

Hanushek, E., Woessman, L.: The role of cognitive skills in economic development. J. Econ. Lit. 46(3), 607-668 (2008)

Heckman, J., Layne-Farrar, A., Todd, P.: Human capital pricing equations with an application to estimating the effect of schooling quality on earnings. Rev. Econ. Stat. 78(4), 562-610 (1996)

Heckman, J., Lochner, L., Todd, P.: Earnings functions and rates of return. J. Hum. Cap. 2(1), 1-31 (2008) 
Horn, L.J., Chen, X., Chapman, C.: Getting Ready to Pay for College: What Students and Their Parents Know About the Cost of College Tuition and What They Are Doing to Find Out, NCES 2003-030 (2003)

Hoxby, C., Turner, S.: Informing students about their college options: a proposal for broadening the expanding college opportunities project. The Hamilton Project Discussion Paper 2013-03 June 2013 (2013)

Hoxby, C., Turner, S.: What high-achieving low-income students know about college. Am. Econ. Rev. (P\&P) 105(5), 514-517 (2015)

Hsieh, C., Klenow, P.: Development accounting. Am. Econ. J. Macroeco. 2(1), 207-223 (2010)

Hungerford, T., Solon, G.: Sheepskin Effects in the Returns to Education. Rev. Econ. Stat. 69(1), 175-177 (1987)

Huntington-Klein, N.: Human capital versus signaling is empirically unresolvable. Empirical Economics (2020)

Ikenberry, S.O., Hartle, T.W.: Too Little Knowledge is a Dangerous Thing: What the Public Think and Knows About Paying for College, American Council on Education, Washington, DC (1998)

Jaeger, D., Page, M.: Degrees matter: new evidence on Sheepskin effects in the returns to education. Rev. Econ. Stat. 78(4), 733-740 (1996)

Jensen, R.: The (Perceived) Returns to Education and the Demand for Schooling. Q. J. Econ. 125(2), 515-548 (2010)

Johnson, J., Rochkind, J., Ott, A.: One Degree of Separation: How Young Americans Who Don't Finish College see their Chances for Success. Public Agenda, San Francisco (2011)

Jung, J., Kim, J., Matejka, F., Sims, C.: Discrete actions in information-constrained problems. Rev. Econ. Stud. 86(6), 2643-2667 (2019)

Kacperczyk, M., Nieuwerburgh, V.an., Veldkamp, L.: A rational theory of mutual funds' attention allocation. Econometrica 84(2), 571-626 (2016)

Koszegi, B.: Utility from anticipation and personal equilibrium. Econ. Theory 44(3), 415-444 (2010)

Koszegi, B., Rabin, M.: A Model of Reference-Dependent Preferences. Q. J. Econ. 121(4), 1133-1165 (2006)

Lloyd-Ellis, H., Roberts, J.: Twin engines of growth: skills and technology as equal partners in balanced growth. J. Econ. Growth 7(2), 87-115 (2002)

Matejka, F.: Rationally inattentive seller: sales and discrete pricing. Rev. Econ. Stud. 83(3), 1125-1155 (2015)

Matejka, F., McKay, A.: Rational inattention to discrete choices: a new foundation for the multinomial logit model. Am. Econ. Rev. 105(1), 272-298 (2015)

Matsuda, K., Mazur, K.: College education and income contingent loans in equilibrium: Theory and Quantitative Evaluation, available at SSRN: https://ssrn.com/abstract=3590541 (2020)

Meghir, C., Pistaferri, L.: Income variance dynamics and heterogeneity. Econometrica 72(1), 1-32 (2004)

Nguyen, T.: Information, Role Models and Perceived Returns to Education: Experimental Evidence from Madagascar," MIT Working Paper (2008)

Piketty, T.: Social mobility and redistributive politics. Q. J. Econ. 110(3), 551-584 (1995)

Porter, C., Serra, D.: Gender differences in the choice of major: the importance of female role models. Am. Econ. J.: Appl. Econ. 12(3), 226-254 (2020)

Ray, D.: Aspirations, poverty and economic change. In: Banerjee, A., Benabou, R., Mookherjee, D. (eds.) Understanding Poverty, pp. 409-422. Oxford University Press, Oxford (2006)

Roderick, M., Nagaoka, J., Coca, V., Moeller, E.: From High School to the Future: Making Hard Work Pay Off. Consortium on Chicago School Research, Chicago (2009)

Saez, E.: Using elasticities to derive optimal income tax rates. Rev. Econ. Stud. 68(234), 205-229 (2001)

Stinebrickner, R., Stinebrickner, T.: Academic performance and college dropout: using longitudinal expectations data to estimate a learning model. J. Labor Econ. 32(3), 601-644 (2014)

Stokey, N.: Technology, skill and long run growth. Becker Friedman institute for research in economics working paper No. 26 (2018)

Trachter, N.: Stepping stone and option value in a model of postsecondary education. Quant. Econ. 6(1), 223-256 (2015)

Wiswall, M., Zafar, B.: Determinants of college major choices: identification from an information experiment. Rev. Econ. Stud. 82(2), 791-824 (2015a)

Wiswall, M., Zafar, B.: How do college students respond to public information about earnings? J. Hum. Cap. 9(2), 117-169 (2015b)

Wiswall, M., Zafar, B.: Human capital investments and expectations about career and family. NBER Working Paper No. 22543 (2016)

Publisher's note Springer Nature remains neutral with regard to jurisdictional claims in published maps and institutional affiliations. 